\title{
Selection of Tolerant and Susceptible Wild Soybean (Glycine soja Siebold \& Zucc.) Accessions under Waterlogging Condition using Vegetation Indices
}

\author{
Se-Hun Kim ${ }^{1 \#}$, Pooja Tripathi ${ }^{1 \sharp}$, Seongmin Yu ${ }^{1}$, Jeong-Min Park ${ }^{1}$, \\ Jeong-Dong Lee ${ }^{1}$, Yong Suk Chung ${ }^{2}$, Gyuhwa Chung ${ }^{3}$, Yoonha Kim* \\ ${ }^{1}$ Department of Applied Biosciences, Kyungpook National University, Daegu, South Korea \\ ${ }^{2}$ Department of Plant Resources and Environment, Jeju National University, Jeju, South Korea \\ ${ }^{3}$ Department of Biotechnology, Chonnam National University, Yeosu, South Korea
}

Received: 28 September 2020

Accepted: 15 November 2020

\begin{abstract}
The waterlogging tolerance and susceptibility of 164 wild soybean accessions were evaluated. All plants were exposed to waterlogging conditions for 14 days, and visual score evaluation and detection of vegetation indices were performed at 14 and 21 days after waterlogging (DAW). According to our results, approximately $90 \%$ of the wild soybean accessions showed a visual score of 1.0-3.5 in both measurements. Among the 26 vegetation indices, only 17 showed statistically high correlation with visual score; however, the maximum $P$-value was less than -0.58 . Therefore, correlation tests were re-performed using the selected wild soybean accessions (waterlogging-tolerant and waterloggingsusceptible accessions). As a result, significantly high $P$-values were detected for anthocyanin reflectance index (ARI1) $(P=0.98069$ at 14 DAW; $P=0.86734$ at 21 DAW), ARI2 $(P=0.98434$ at $14 \mathrm{DAW} ; P=0.87934$ at $21 \mathrm{DAW})$, photochemical reflectance index $(P=-0.9801$ at $14 \mathrm{DAW}$; $P=-0.9268$ at $21 \mathrm{DAW})$, and simple ratio pigment index $(P=-0.8841$ at $14 \mathrm{DAW} ; P=-0.81292$ at 21 DAW). Root morphological traits also showed significant differences between waterloggingtolerant and waterlogging-susceptible accessions. In waterlogging-tolerant accessions, root length was 3.7-5.5-fold higher than that in waterlogging-susceptible accessions. Furthermore, waterlogging-tolerant accessions showed a $14.3 \%-56.3 \%$ increase in projected area compared with in waterlogging-susceptible accessions.
\end{abstract}

\footnotetext{
\#These authors equally contributed to this work *e-mail: kyh1229@knu.ac.kr
} 


\section{Graphical abstract}

Evaluation of waterlogging tolerance and susceptible

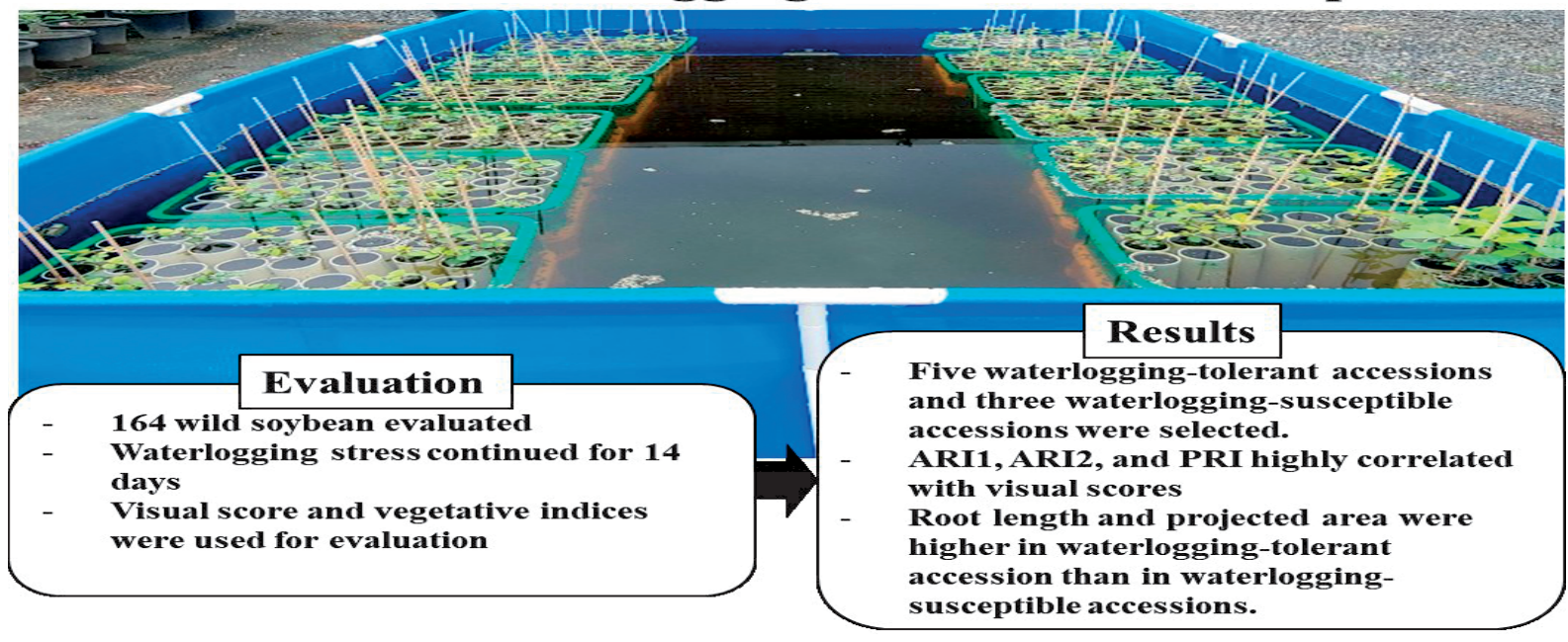

Keywords: root morphological traits, vegetation index, waterlogging, WinRHIZO

\section{Introduction}

Waterlogging stress is a major problem for the production of various crops, including cotton [1, 2], maize [2], oats [3], soybean [4], and sugarcane [5]. For soybean, waterlogging can result in heavy yield loss $(17 \%-57 \%)$; therefore, several waterlogging-tolerant cultivars have been screened by soybean breeders $[6$, 7]. Furthermore, candidate quantitative trait loci also have been reported; however, the detailed physiological and genetic mechanisms of waterlogging in soybeans remain unknown [6, 7].

Waterlogging stress is caused by high water levels in the cultivated field during heavy precipitation, river flooding, and excessive irrigation [4]. Flash waterlogging in well-drained field conditions does not hinder the growth and development of soybean plants; however, waterlogging for an extended period of long restricts ordinary growth and development of the crop [8]. Waterlogging conditions in arable land result in the covering of soil pores with water; this leads to anoxia or hypoxia in the soil [4, 8]. Basically, plants need to absorb oxygen from the soil for various physiological processes, including mitochondrial respiration, which generates energy resources, such as nicotinamide adenine dinucleotide and adenosine triphophate. In the absence of oxygen, plants switch to an alternative physiological process called fermentation, which produces ethanol and lactate [9, 10]. Even with this alternative pathway, plants are unable to survive long-term waterlogging stress due to the lack of energy resources [11]. To cope with this, plants induce morphological changes in their shoot and root for capturing or transferring oxygen from the atmosphere to the plant body, particularly in the root zone $[4,5$,
11]. The production of aerenchyma cells in the shoot and root is the most common response to waterlogging, as observed in rice, maize, and soybean [2, 11, 12]. Therefore, selecting soybean accessions that can easily produce aerenchyma cells in their body during waterlogging conditions will aid in the development of waterlogging-resistant cultivars.

Many plant breeders have evaluated waterloggingtolerant and waterlogging-susceptible soybean (Glycine max) accessions generated via mapping population and reported several QTLs in chromosome 3, 5, 10, 11, 13, and 18 , which are linked to waterlogging tolerance [7, 13-15]. However, the evaluation of waterlogging resistance and production of mapping population in wild soybeans (Glycine soja) remain unexplored to date. Wild soybeans are grown in a complex geography as well as in a wide range of climatic conditions; therefore, they often show improved stress tolerance than other cultivars [16]. Additionally, wild accessions confer to a wide range of genetic resources in major crops and are regarded as an important resource for plant breeding [17]. Wild soybean is used as food and feed with Glycine max and is also regarded as the progenitor of Glycine max [18]. Therefore, wild soybean has been considered a treasure of genetic resources, with high oil content, disease resistance, and environmental stress tolerance [18]. Despite wild soybean being an important genetic resource, adequate information on its resistance to waterlogging conditions is lacking. Therefore, this experiment was performed to evaluate waterlogging tolerance and sensitivity in wild soybean accessions. A total of 164 wild soybean accessions were evaluated using a state-of-the-art technology for wild soybean phenotyping. 


\section{Experimental Procedures}

\section{Plant Materials and Growth Conditions}

Initially we planted 466 wild soybean seeds per replication; however, the data for only 164 seeds for three replications were obtained as the germination rate was low (Fig. 1). Accessions were donated by the Gene Bank of Korea, plant introduction (PI) was from USDA-ARS, Chung's wild germplasm collection (CW) was from Chonnam National University, Korea [19], and YWSs were from Yeungnam University (Prof. EuiHo Park) (Table S1). Seeds were scarified with a help of a nail clipper to enhance water uptake. The seeds were sown into polyvinyl chloride (PVC) pipes $[6 \mathrm{~cm}$ (diameter) $\times 40 \mathrm{~cm}$ (height)] containing horticultural soil (Tobirang, Baekkwang Fertility, South Korea). When the seeds germinated, all pots were placed in a greenhouse located in the research center of Kyungpook National University, Daegu, South Korea. When the wild soybeans reached the V1 growth stage, all pots were placed in a pool of water for 2 weeks to ensure waterlogging conditions. Our experiment was conducted in three replicates per accession $(n=1)$. The 326, 339, and 335 wild soybean accessions were germinated in each replication. During the three replicates, only 164 wild soybean accessions were consistently germinated due to non-uniform seed germination (Fig. 1). The experiment began on June 3, 2019 and ended on September 5, 2019.

Analysis of Vegetation Index, Chlorophyll Content, and Visual Scores

To evaluate stress levels, we measured vegetation indices, chlorophyll content, and visual scores of

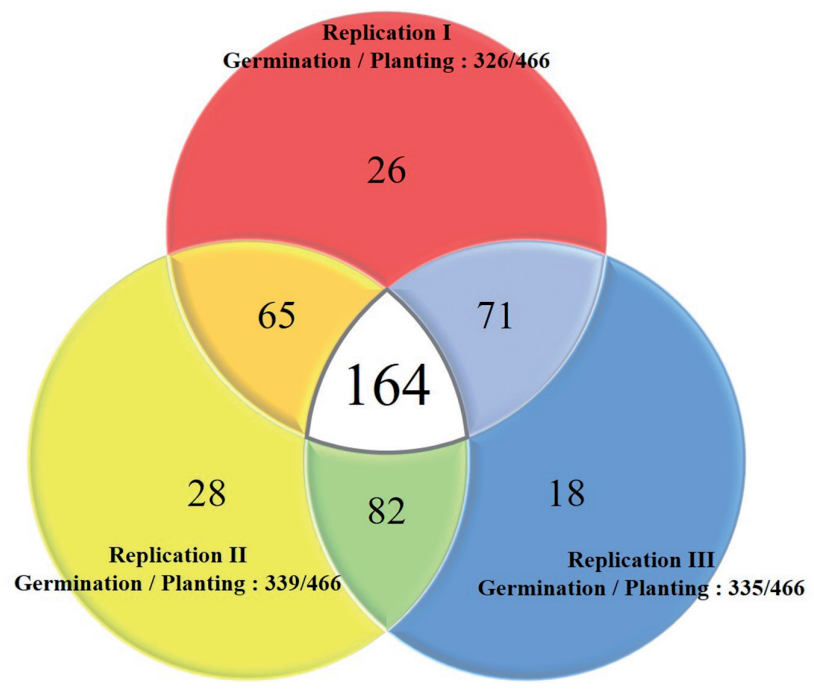

Fig. 1. Information on the number of germinated seeds for the three replicates. We used 164 seeds to evaluate waterlogging tolerance and susceptibility. soybean plants before and after waterlogging [(14 and 21 days after waterlogging (DAW)]. First, we measured various vegetation indices using PolyPen (RP410, Photon Systems Instruments, Czech Republic). To gather uniform data, we selected the second trifoliate leaf from every plant for measurement, and the average value of three different points was used for analysis. We used a chlorophyll meter (MC-100, Apogee Instruments Inc., USA) for determining the chlorophyll content and used the same leaf position for chlorophyll content measurement. All relevant data were collected from three replicates $(n=3)$. The equation of vegetation indices is shown in Table S2. In addition, we assessed the visual scores of soybean plants at 14 and 21 DAW and used a 1-5 scoring scale based on the extent of plant damage (Fig. 2). The wild soybean accessions were exposed to waterlogging for 14 days and scored 1 to 5 based on the damage symptom at 14 and 21 DAW. A visual score of 1 indicates no plant damage (healthy plant), score 3 indicates a $50 \%$ change in leaf color, and 5 indicates more than $80 \%$ of leaf color is yellow and red. Data were collected three times and are presented as the average \pm standard error $(n=3)$.

\section{Determination of Shoot and Root Phenotype}

Shoot and root samples were harvested at 21 DAW. We cut the shoot and root with a pair of scissors and immediately captured shoot images at a mini-studio to prevent drying of the leaves. The collected shoot images were analyzed using the WinRHIZO pro software (Regent Instruments Inc. Canada). For root collection, we poured soil from the pipes into a sieve and carefully removed the root from the soil. The collected roots were thoroughly washed with clean water to remove adhering soil particles and were stored in a plastic bag with distilled water to prevent them from drying. Root morphological traits were analyzed using the WinRHIZO pro software with captured images from a scanner (Expression 12000XL, Epson, Japan). The soil particles were further removed from the root samples and placed in a transparent tray (30 cm long $\times 20 \mathrm{~cm}$ wide) containing clean water for scanning.

\section{Statistics Analysis}

To determine the differences in data, we performed analysis of variance (ANOVA) (SAS release 9.4; SAS, Gary, NC, USA) for the visual scores and all phenotypic data. Mean value differences were determined using the Student's t-test at significance levels of $P<0.05$ and $P<0.01$. In addition, correlation analysis was conducted at a significance level of $P<0.05$. We performed statistical analysis with the data from the three replicates in order to obtain reliable results. 

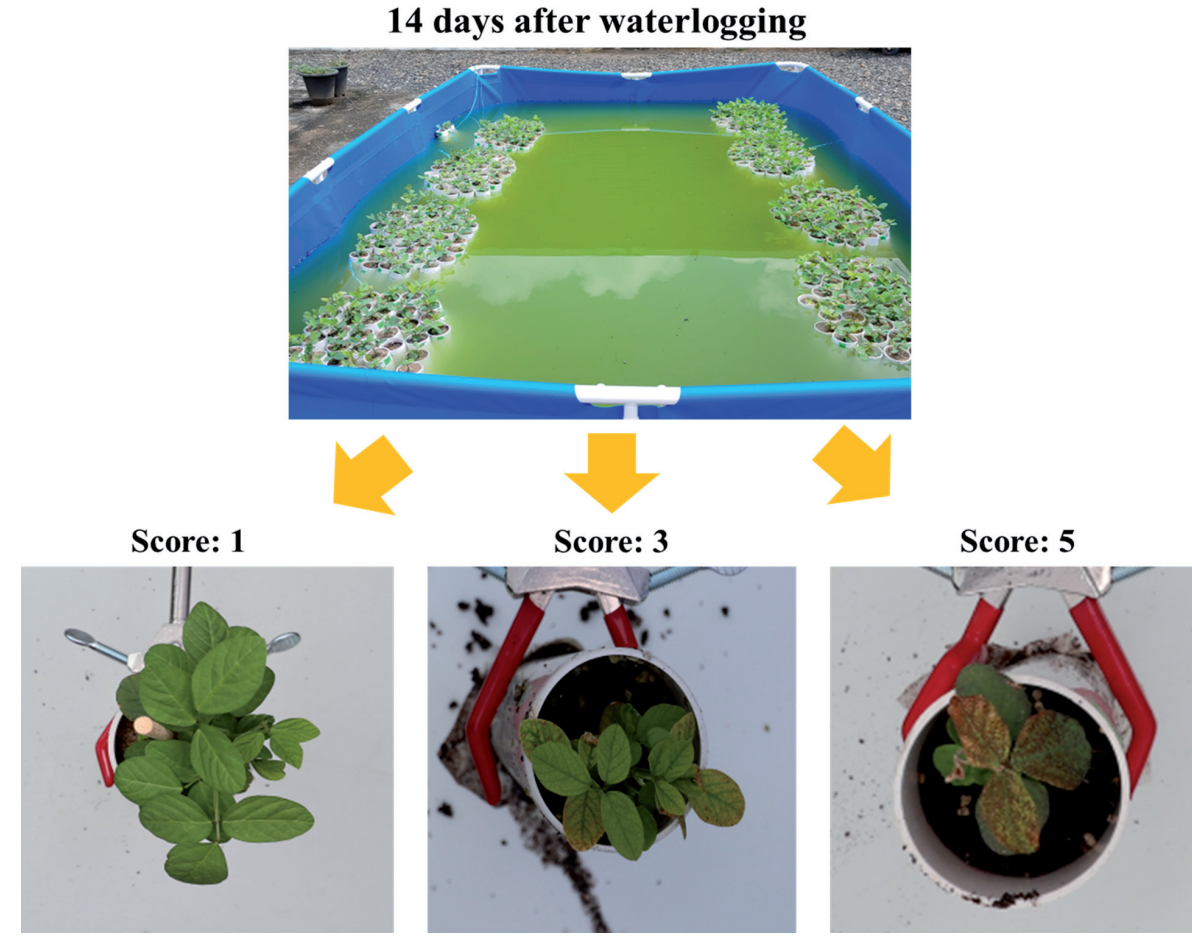

Fig. 2. Evaluation of waterlogging tolerance in wild soybeans. The wild soybean accession were exposed to waterlogging for 14 days and scored 1-5 based on the damage symptoms at 14 and 21 days after waterlogging. A visual score of 1 indicates no plant damage (healthy plant), score of 3 indicates a $50 \%$ change in leaf color was changed, score of 5 indicates over $80 \%$ of leaf color is yellow and red.

\section{Results}

\section{Influence of Waterlogging Stress on Chlorophyll Content and Vegetation Index}

According to ANOVA, all vegetation indices and chlorophyll contents showed significant differences in the 164 wild soybean accessions before waterlogging treatment (BW) (Table 1). At 14 and 21 DAW, all vegetation indices and chlorophyll contents showed significant differences at in 164 wild soybean accessions $(P<0.0001)$ (Tables 2 and 3).

\section{Selection of Waterlogging-Tolerant and Waterlogging-Susceptible Accessions}

The condition of the plants was visually analyzed and rated on a scale of 1-5. Score 1 indicated that all plants showed no stress injury and score 5 denoted dead plants [20] (Fig. 2). The 466 wild soybeans were evaluated for waterlogging tolerance and susceptibility at an early growth stage. Based on leaf injury (yellow and red spots), score (1.0-2.0) was regarded as resistant to waterlogging and score (2.1-4.0) was regarded as moderately resistant to waterlogging. Likewise, score (4.1-5.0) was considered as susceptible to waterlogging. In this study, $22.0 \%, 75.6 \%$, and $2.4 \%$ of wild soybean accessions were evaluated as resistant, moderately resistant, and susceptible to waterlogging, respectively at 14 DAW (Fig. 3). At 21 DAW, 34.8\%, 64.0\%, and 1.2\% of wild soybean accessions were resistant, moderately resistant, and susceptible to waterlogging, respectively (Fig. 3). Most of the wild soybean accessions were resistant or moderately resistant when exposed to waterlogging for 14 days, whereas only $1.2 \%$ of soybean accessions were extremely susceptible to waterlogging stress. Based on the visual scores, five accessions that were highly tolerant to waterlogging stress (CW11598, CW14633, YWS 76, YWS 469, and YWS 602) and 3 accessions that were sensitive to waterlogging stress (CW11948, YWS 85, and YWS 545) were selected.

\section{Correlation Test between the Visual Scores and Vegetation Indices in 164 Wild Soybean Accessions}

A correlation analysis test between various vegetation indices and visual scores was performed to identify appropriate vegetation indices for stress resistance prediction. As shown in Table 4, many vegetation indices showed high correlation with visual scores. At 14 DAW, all vegetation indices, except chlorophyll content, $(r=-0.06056, P<0.411)$ showed significant correlation with visual scores (Table 4). In particular, photochemical reflectance index (PRI) revealed the highest correlation $(r=-0.57181, P<0.0001)$ with visual scores (Table 4). The same result was observed at 21 DAW; however, the correlation values of each vegetation index generally decreased compared with those at 14 DAW (Table 4). Similar to 14 DAW, the correlation between PRI and visual score showed a maximum value $(r=-0.37995$, 


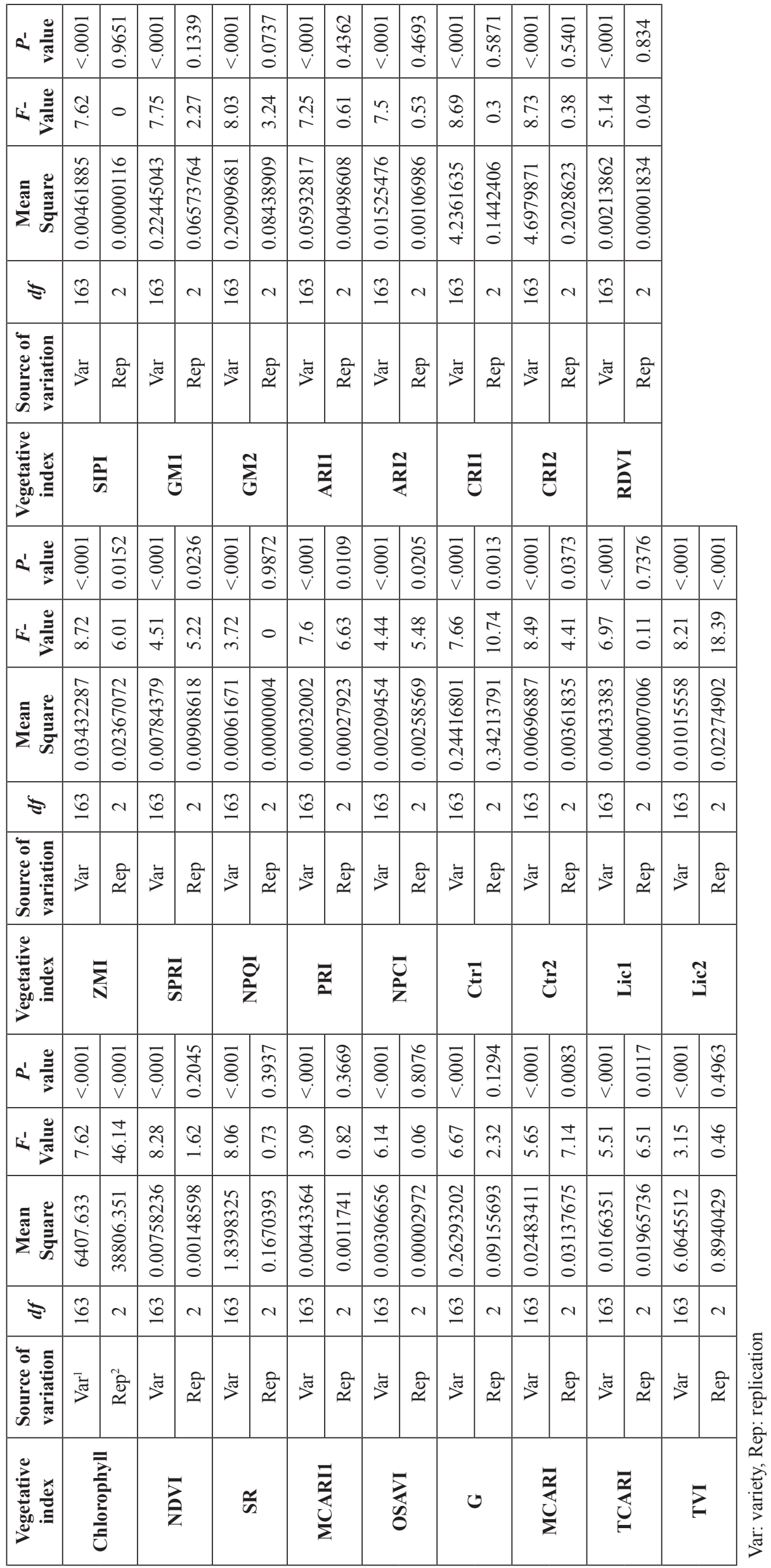




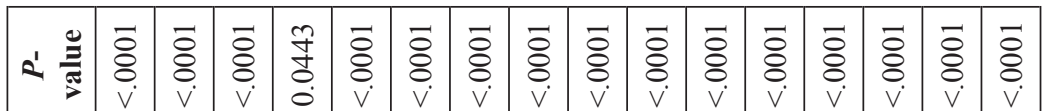

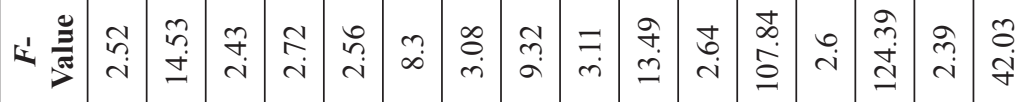

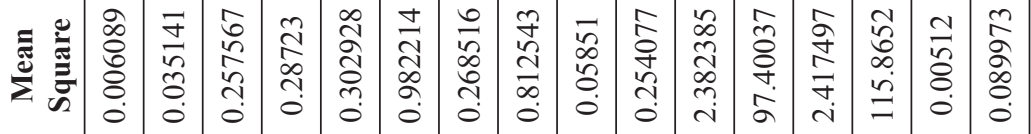

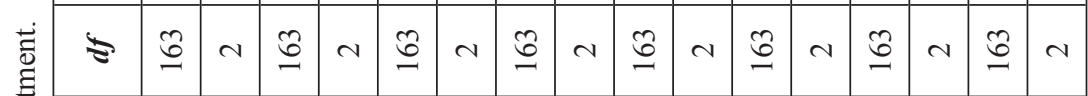

言旁

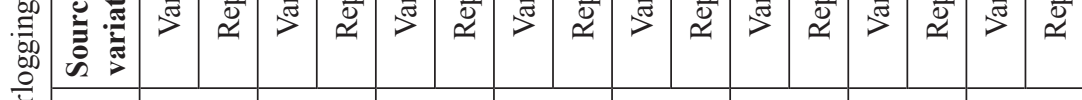

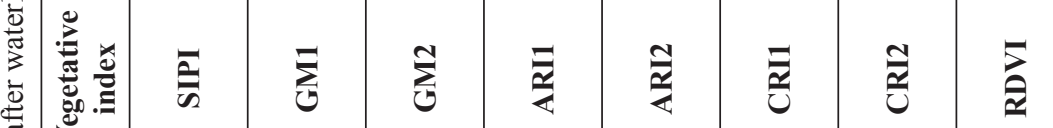

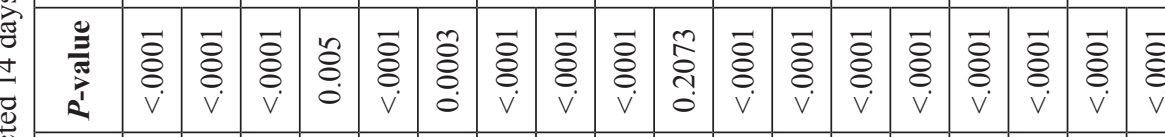

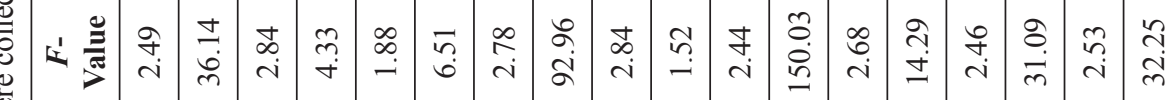

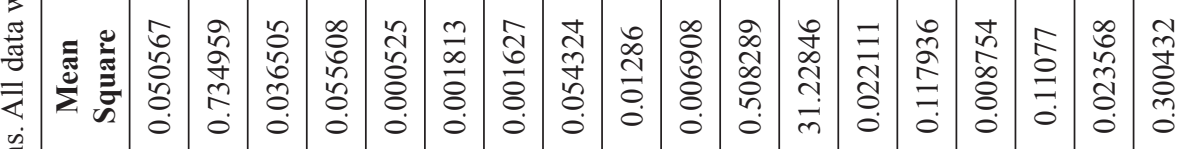

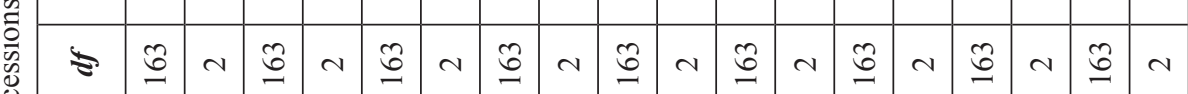

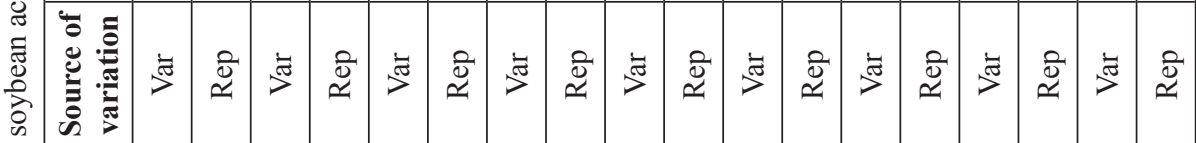

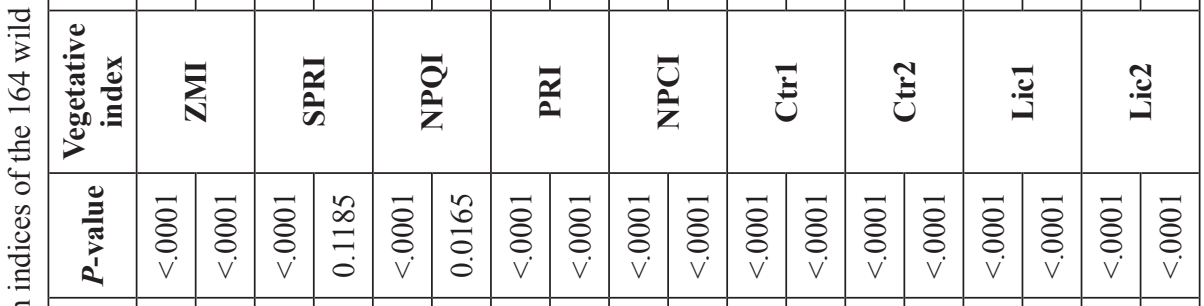

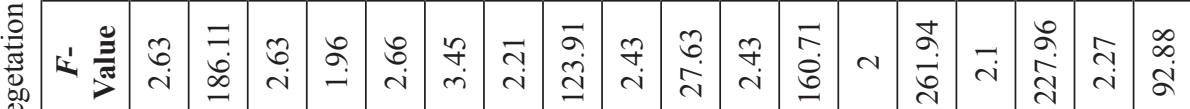

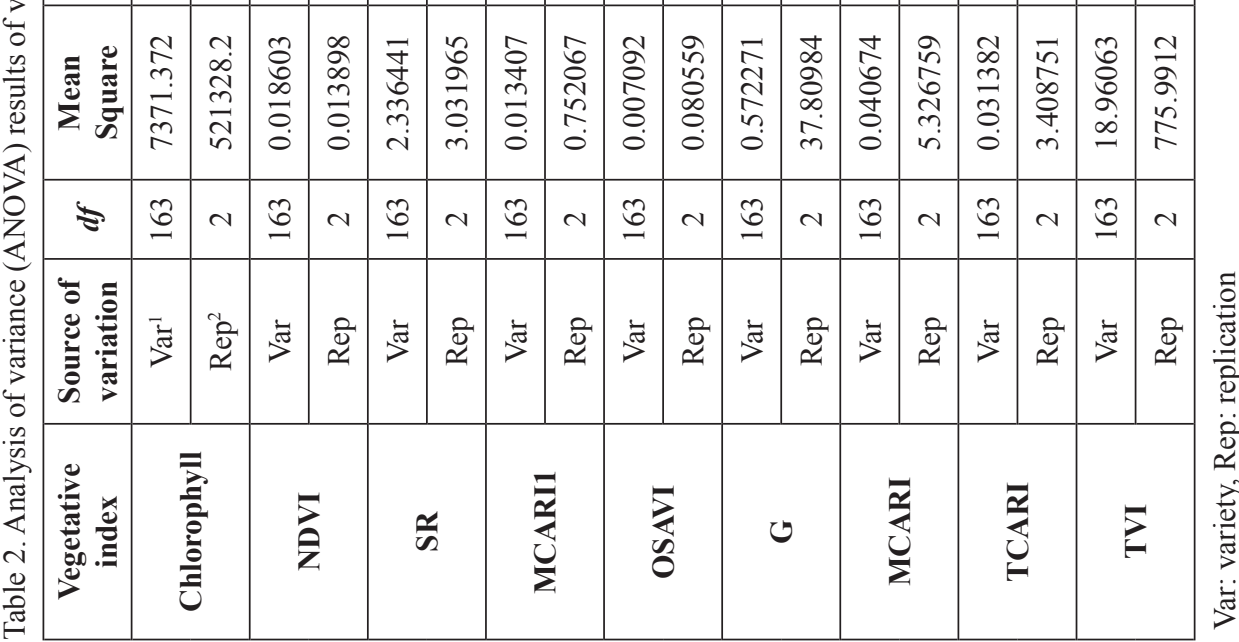




\begin{tabular}{|c|c|c|c|c|c|c|c|c|c|c|c|c|c|c|c|c|}
\hline$\alpha \frac{\mathscr{E}}{\sigma}$ & $\begin{array}{l}\vec{\delta} \\
\text { v } \\
\text { v }\end{array}$ & $\begin{array}{l}\overrightarrow{8} \\
\text { o. } \\
\text { v }\end{array}$ & $\begin{array}{l}\overrightarrow{8} \\
\text { v } \\
\text { v }\end{array}$ & $\begin{array}{l}\overrightarrow{8} \\
\text { v } \\
\text { v }\end{array}$ & $\begin{array}{l}\vec{\delta} \\
\dot{0}\end{array}$ & $\begin{array}{l}\vec{\delta} \\
\dot{\nabla}\end{array}$ & $\begin{array}{l}\vec{\delta} \\
\dot{\nabla}\end{array}$ & $\begin{array}{l}\overrightarrow{8} \\
\dot{0}\end{array}$ & $\begin{array}{l}\vec{\delta} \\
\dot{0}\end{array}$ & $\begin{array}{l}\overrightarrow{8} \\
\dot{8} \\
\text { v }\end{array}$ & $\begin{array}{l}\vec{\Xi} \\
\text { v } \\
\text { v }\end{array}$ & $\begin{array}{l}\vec{\Xi} \\
\dot{\Xi} \\
\dot{v}\end{array}$ & $\begin{array}{l}\vec{\Xi} \\
\bar{\Xi} \\
v\end{array}$ & $\begin{array}{l}\vec{\Xi} \\
\bar{\Xi} \\
v\end{array}$ & $\begin{array}{l}\overrightarrow{8} \\
\dot{8} \\
\mathrm{v}\end{array}$ & $\begin{array}{l}\overrightarrow{8} \\
\text { v }\end{array}$ \\
\hline 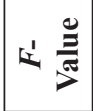 & $\underset{i}{ \pm}$ & 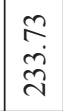 & $\begin{array}{l}\text { d } \\
\text { i }\end{array}$ & $\begin{array}{l}\tilde{\hat{~}} \\
\text { nิ }\end{array}$ & $\begin{array}{l}\infty \\
i n \\
i\end{array}$ & 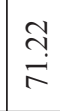 & $\hat{n}$ & $\stackrel{n}{0}$ & 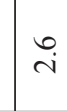 & $\vec{a}$ & $\frac{n}{i}$ & \begin{tabular}{|l}
$\alpha$ \\
$\infty$ \\
$\infty$ \\
$\infty$ \\
$\sim$
\end{tabular} & $\vec{i}$ & 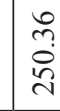 & $\stackrel{\hat{i}}{\hat{i}}$ & $\begin{array}{l}q \\
\dot{f} \\
\text { r. }\end{array}$ \\
\hline & $\begin{array}{l}\tilde{\delta} \\
\tilde{0} \\
\delta \\
\delta \\
0\end{array}$ & 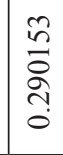 & $\begin{array}{l}\stackrel{\text { f }}{\Xi} \\
\stackrel{\sim}{\Xi}\end{array}$ & 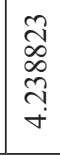 & 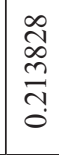 & $\begin{array}{l}\hat{\infty} \\
\vec{D} \\
\stackrel{0}{0} \\
\dot{\omega}\end{array}$ & $\begin{array}{l}\frac{+}{+} \\
\frac{+}{\infty} \\
\frac{0}{0}\end{array}$ & 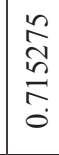 & $\begin{array}{l}\underset{\mathbb{N}}{\hat{N}} \\
\text { o. } \\
0\end{array}$ & $\begin{array}{l}0 \\
0 \\
0 \\
0 \\
0 \\
0\end{array}$ & $\begin{array}{l}\text { 突 } \\
\text { مે } \\
\text { ch }\end{array}$ & 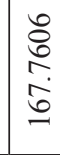 & 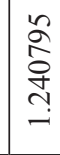 & 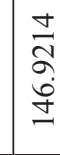 & $\begin{array}{l}\hat{\imath} \\
\bar{a} \\
0 \\
0\end{array}$ & $\begin{array}{l}n \\
2 \\
\delta \\
0 \\
0 \\
0\end{array}$ \\
\hline & 3 & $N$ & 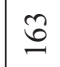 & $N$ & శ్ర & $N$ & 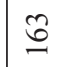 & $N$ & 3 & $\sim$ & 3 & $\sim$ & 6 & $N$ & $\stackrel{3}{6}$ & $\sim$ \\
\hline
\end{tabular}

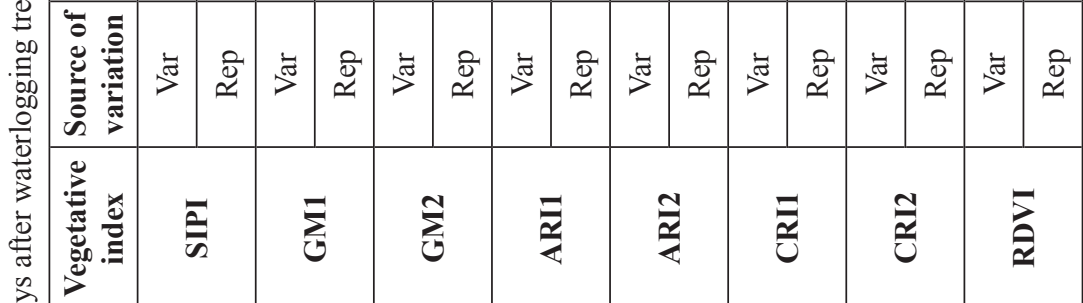

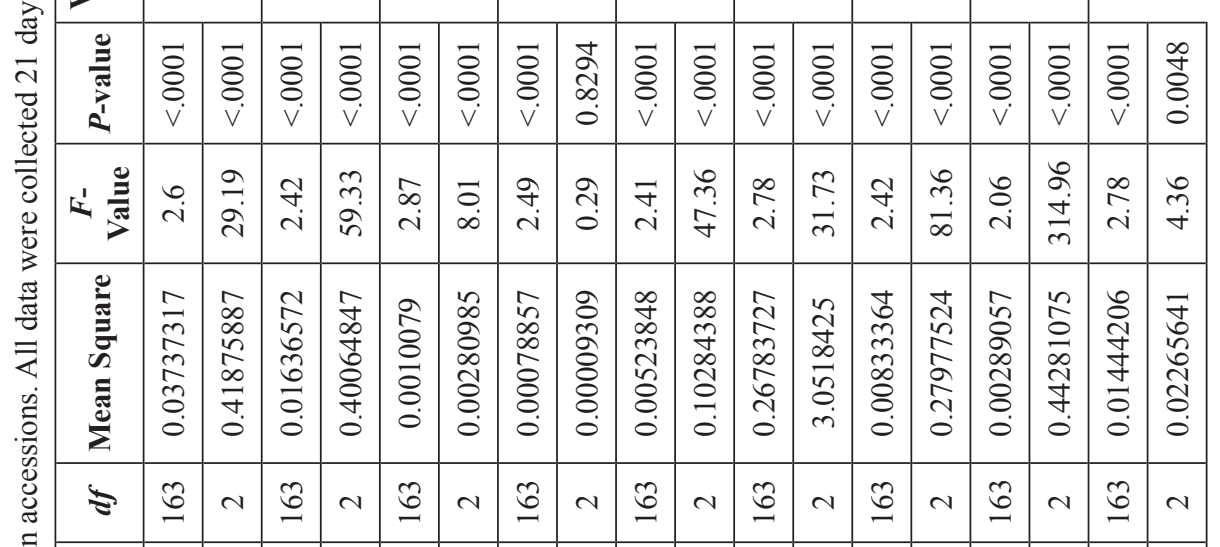

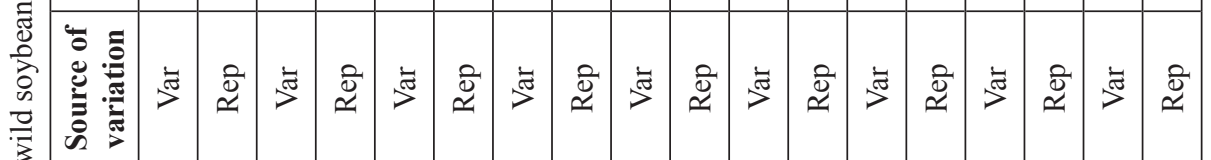

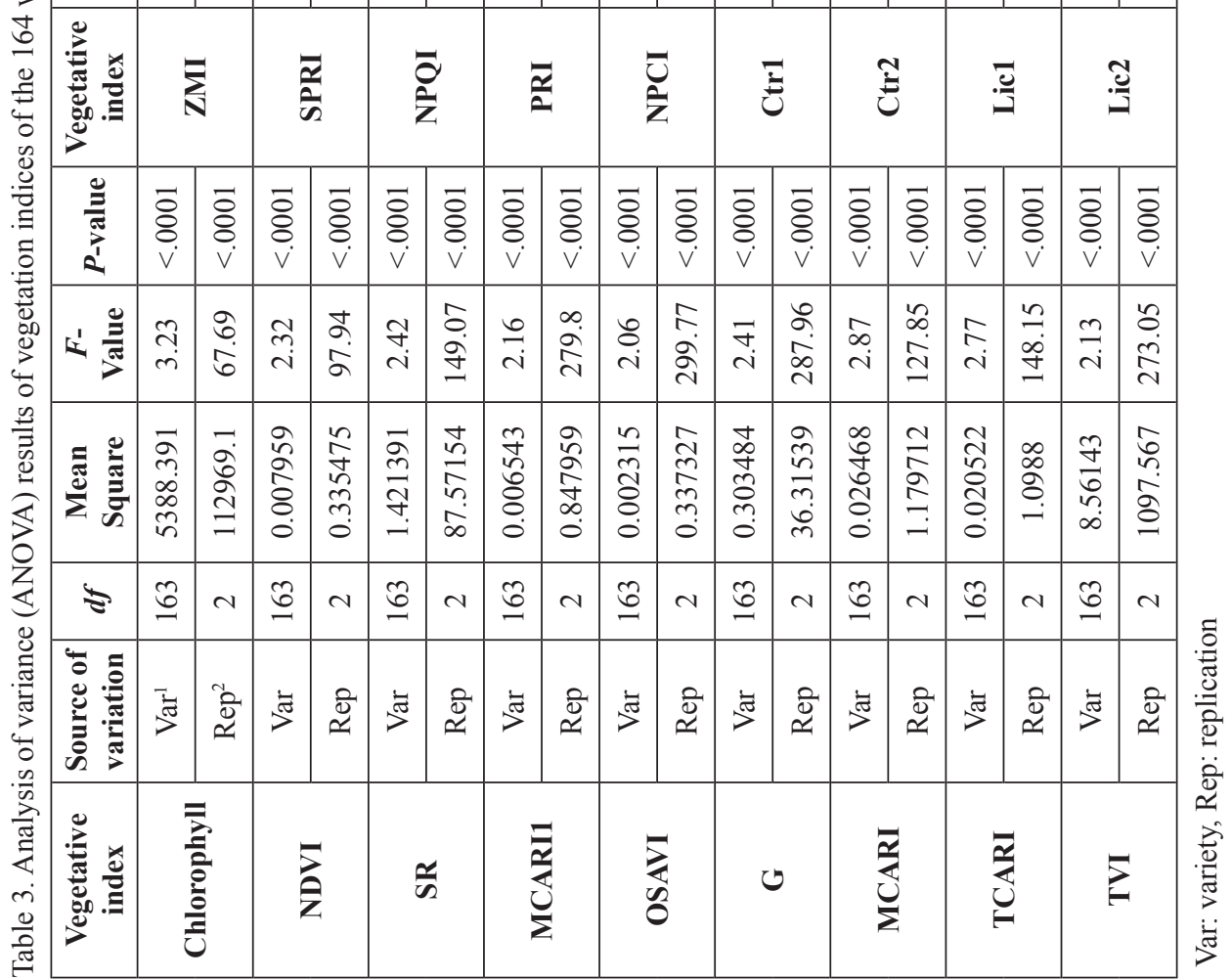



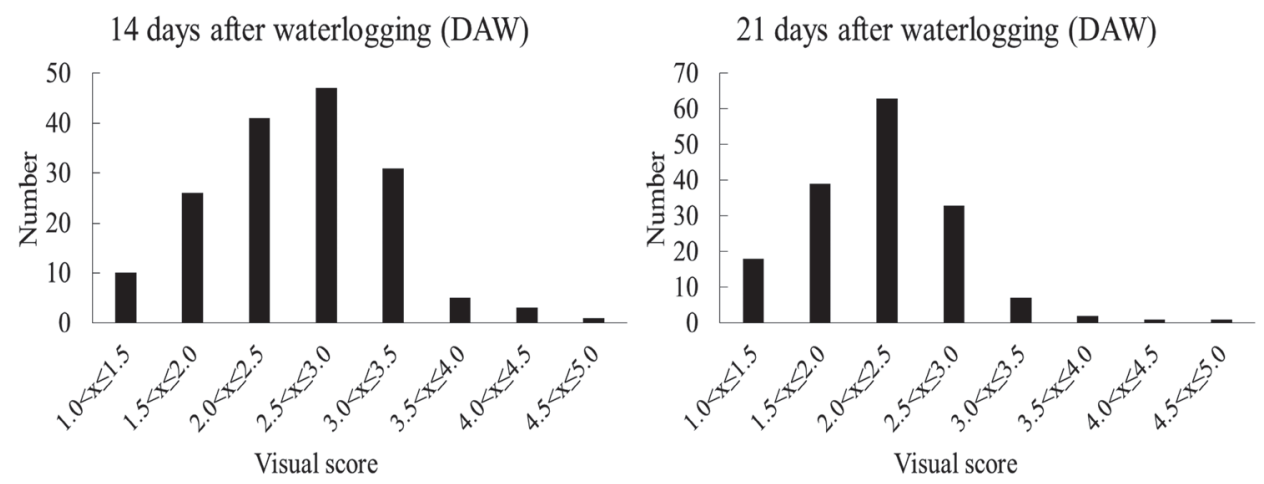

Fig. 3. Distribution of the visual scores of the 164 wild soybean accessions at 14 and 21 days after waterlogging.

$P<0.0001)$ at 21 DAW but decreased when compared with that at 14 DAW (Table 4).

Correlation Test between the Visual Scores and Vegetation Indices Among Eight Selected Wild Soybean Accessions

Significant correlation was observed for the comparison of vegetation indices and visual score ratings in 164 wild soybean accessions, but the value was low due to moderate visual ratings. The vegetation indices of the eight selected wild soybeans were used for correlation testing. Interestingly, only four vegetation indices, namely simple ratio pigment index (SPRI), anthocyanin reflectance index 1 (ARI1), anthocyanin reflectance index 2 (ARI2), and PRI showed significant correlations with visual scores. At 14 DAW, SPRI $(r=-0.8841, \quad P<0.0082), \quad$ ARI1 $\quad(r=0.98069$, $P<0.0001)$, ARI2 $(r=0.98069, P<0.0001)$, and PRI $(r=-0.9801, P<0.0001)$ showed significant correlations with visual scores (Table 5). At 21 DAW, similar results were observed; therefore, these four vegetation indices can better reflect stress injury than others.

\section{Changes in Vegetation Indices during Waterlogging Stress in Selected Wild Soybean Accessions}

The influence of various vegetation indices for waterlogging is presented in Fig. 4. For SPRI1, most of the waterlogging-tolerant accessions did not show significant difference between BW and after waterlogging. Moreover, compared with BW, the SPRI value significantly decreased in all of the waterloggingsusceptible accessions at 14 and 21 DAW (Fig. 4). On the other hand, the ARI1 and ARI2 values showed an opposite trend to SPRI1 in waterlogging-susceptible accessions. Similar to SPRI1, most of the tolerant accessions did not show any significant difference between BW and after waterlogging (Fig. 4). However, the values of ARI1 and ARI2 increased 2.0-8.0 fold when accessions were exposed to waterlogging (14 DAW) or were past the waterlogging stress threshold (21 DAW) (Fig. 4). PRI revealed distinguishing differences between waterlogging-tolerant and waterlogging-susceptible accessions. Overall, increased or similar PRI values were found in waterloggingtolerant accessions when comparing before and after waterlogging (Fig. 4). However, in the waterloggingsusceptible accessions, all PRI values were positive BW but negative after waterlogging (Fig. 4). Finally, most of the waterlogging-tolerant accessions showed similar values when exposed to waterlogging stress; however, the values of susceptible accessions fluctuated. PRI showed a negative value in the waterlogging-susceptible accessions upon waterlogging.

\section{Root Characteristics of Selected Wild Soybean Accessions}

Waterlogging-tolerant and waterlogging-susceptible accessions showed different root morphological traits, as shown in (Fig. 5). Comparison between tolerant and susceptible accessions revealed that root length significantly increased in waterlogging-tolerant accessions, specifically in accession 884 , which showed the highest root length (Fig. 5). Root length was not statistically different in susceptible accessions. In the case of the projected area, most of the tolerant accessions, except accession 659, showed higher projected area than susceptible accessions. Likewise, accession 884 and 1022 showed the maximum values in the tolerant accessions Fig. 5. Overall, the projected area was ranged from 7.7 to $15.1 \mathrm{~cm}^{2}$ in waterloggingtolerant accessions, whereas susceptible accessions ranged from 5.1 to $6.6 \mathrm{~cm}^{2}$. Therefore, the projected area was increased by $14.3 \%-56.3 \%$ in waterloggingtolerant accessions compared with in susceptible accessions, particularly accession 888 (Fig. 5). The link average length ranged from 0.23 to $0.261 \mathrm{~cm}$, and accessions 659 and 1116 showed the maximum values, whereas others were not clearly distinguished (Fig. 5). In susceptible accessions, the link average length ranged from 0.185 to $0.247 \mathrm{~cm}$, and accession 504 showed the lowest value compared with other susceptible accessions (Fig. 5). Compared between accessions 651 and 504, the link average length was increased by $29.1 \%$. 
Table 4. Correlation between the vegetation indices and visual scores of the 164 wild soybeans accessions after waterlogging.

\begin{tabular}{|c|c|c|}
\hline \multirow[b]{2}{*}{ Vegetative index } & \multicolumn{2}{|c|}{ Pearson correlation coefficient $P$-value } \\
\hline & $\begin{array}{c}14 \text { days after waterlogging } \\
\text { treatment }\end{array}$ & $\begin{array}{l}21 \text { days after waterlogging } \\
\text { treatment }\end{array}$ \\
\hline \multirow{2}{*}{ Chlorophyll content } & -0.06056 & -0.0509 \\
\hline & 0.4411 & 0.5175 \\
\hline SIPI & -0.4103 & -0.31213 \\
\hline Structure Insensitive Pigment Index & $<.0001$ & $<.0001$ \\
\hline NDVI & -0.42502 & -0.30161 \\
\hline Normalized Difference Vegetation Index & $<.0001$ & $<.0001$ \\
\hline SPRI & -0.53908 & -0.26154 \\
\hline Simple Ratio Pigment Index & $<.0001$ & 0.0007 \\
\hline SR & -0.41052 & -0.29212 \\
\hline Simple Ratio Index & $<.0001$ & 0.0001 \\
\hline ARI1 & 0.55379 & 0.31649 \\
\hline Anthocyanin Reflectance Index & $<.0001$ & $<.0001$ \\
\hline ARI2 & 0.55609 & 0.32397 \\
\hline Anthocyanin Reflectance Index & $<.0001$ & $<.0001$ \\
\hline GM2 & -0.41348 & -0.24526 \\
\hline Gitelson \& Merzlyak Index & $<.0001$ & 0.0015 \\
\hline MCARI1 & -0.47011 & -0.19991 \\
\hline Modified Chlorophyll Absorption in Reflectance Index & $<.0001$ & 0.0103 \\
\hline PRI & -0.57181 & -0.37995 \\
\hline Photochemical Reflectance Index & $<.0001$ & $<.0001$ \\
\hline OSAVI & -0.48381 & -0.3362 \\
\hline Optimized Soil-Adjusted in Reflectance Index & $<.0001$ & $<.0001$ \\
\hline NPCI & 0.52924 & 0.27952 \\
\hline Normalized Phaeophytinization Index & $<.0001$ & 0.0003 \\
\hline Ctr1 & 0.41741 & 0.17459 \\
\hline Carter Stress Index & $<.0001$ & 0.0254 \\
\hline Ctr2 & 0.45582 & 0.30313 \\
\hline Carter Stress Index & $<.0001$ & $<.0001$ \\
\hline G & -0.48957 & -0.24321 \\
\hline Greenness Index & $<.0001$ & 0.0017 \\
\hline Lic1 & -0.47228 & -0.33052 \\
\hline Lichtenthaler Index & $<.0001$ & $<.0001$ \\
\hline Lic2 & -0.44309 & -0.25319 \\
\hline Lichtenthaler Index & $<.0001$ & 0.0011 \\
\hline RDVI & -0.49601 & -0.31272 \\
\hline Renormalized Difference Vegetation Index & $<.0001$ & $<.0001$ \\
\hline
\end{tabular}


Table 5. Correlation between the vegetation indices and visual scores of the eight selected waterlogging-tolerant and waterloggingsusceptible wild soybean accessions.

\begin{tabular}{|c|c|c|}
\hline \multirow[b]{2}{*}{ Vegetative index } & \multicolumn{2}{|c|}{ Pearson correlation coefficient $P$-value } \\
\hline & $\begin{array}{l}14 \text { days after waterlogging } \\
\text { treatment }\end{array}$ & $\begin{array}{c}21 \text { days after waterlogging } \\
\text { treatment }\end{array}$ \\
\hline \multirow{2}{*}{ Chlorophyll content } & -0.68343 & 0.21608 \\
\hline & 0.0905 & 0.6417 \\
\hline SIPI & -0.23709 & -0.65002 \\
\hline Structure Insensitive Pigment Index & 0.6087 & 0.114 \\
\hline NDVI & -0.5546 & -0.76404 \\
\hline Normalized Difference Vegetation Index & 0.1963 & 0.0455 \\
\hline SPRI & -0.8841 & -0.81292 \\
\hline Simple Ratio Pigment Index & 0.0082 & 0.0262 \\
\hline SR & -0.6716 & -0.76532 \\
\hline Simple Ratio Index & 0.0985 & 0.0449 \\
\hline ARI1 & 0.98069 & 0.86734 \\
\hline Anthocyanin Reflectance Index & $<.0001$ & 0.0047 \\
\hline ARI2 & 0.98434 & 0.87934 \\
\hline Anthocyanin Reflectance Index & $<.0001$ & 0.0032 \\
\hline GM2 & -0.8254 & -0.642 \\
\hline Gitelson \& Merzlyak Index & 0.0222 & 0.12 \\
\hline MCARI1 & 0.66774 & -0.07336 \\
\hline Modified Chlorophyll Absorption in Reflectance Index & 0.1012 & 0.8758 \\
\hline PRI & -0.9801 & -0.9268 \\
\hline Photochemical Reflectance Index & $<.0001$ & 0.0027 \\
\hline OSAVI & -0.2792 & -0.40402 \\
\hline Optimized Soil-Adjusted in Reflectance Index & 0.5443 & 0.3687 \\
\hline NPCI & 0.88266 & 0.80303 \\
\hline Normalized Phaeophytinization Index & 0.0085 & 0.0296 \\
\hline Ctr1 & 0.12392 & -0.7142 \\
\hline Carter Stress Index & 0.7912 & 0.0714 \\
\hline Ctr2 & 0.51651 & -0.3717 \\
\hline Carter Stress Index & 0.2353 & 0.4117 \\
\hline G & -0.3645 & -0.07522 \\
\hline Greenness Index & 0.4215 & 0.8727 \\
\hline Lic1 & -0.3097 & -0.46056 \\
\hline Lichtenthaler Index & 0.499 & 0.2983 \\
\hline Lic2 & -0.94 & -0.82187 \\
\hline Lichtenthaler Index & 0.0016 & 0.0233 \\
\hline RDVI & -0.2474 & -0.32749 \\
\hline Renormalized Difference Vegetation Index & 0.5928 & 0.4734 \\
\hline
\end{tabular}



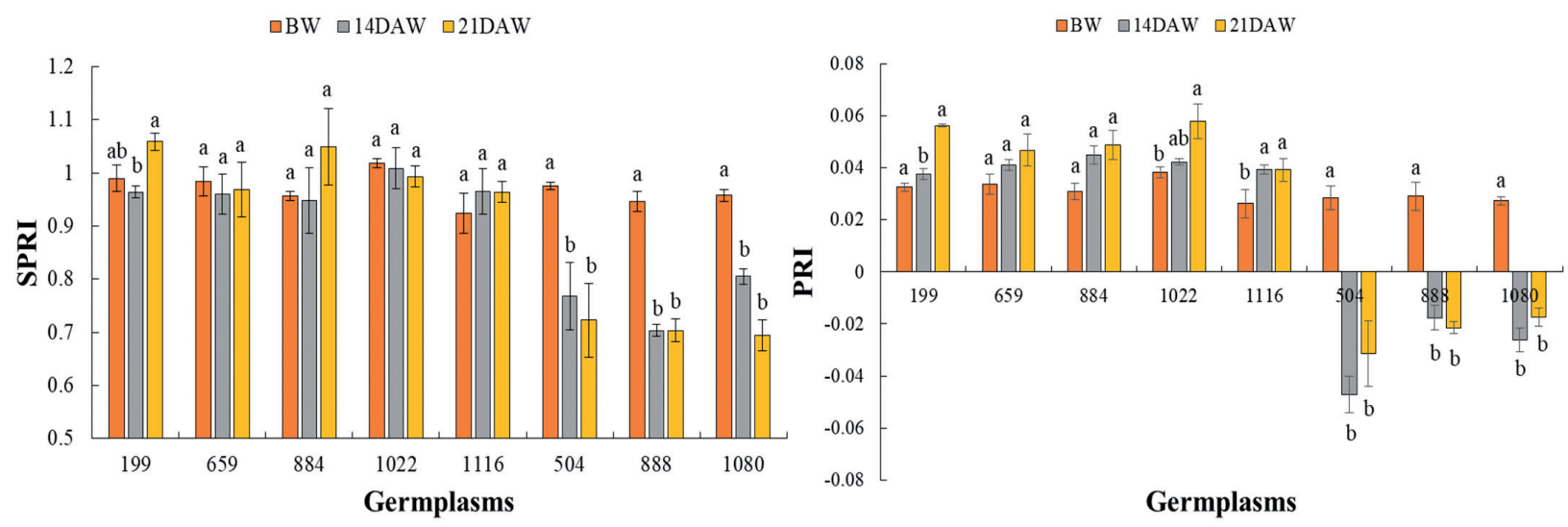

Germplasms
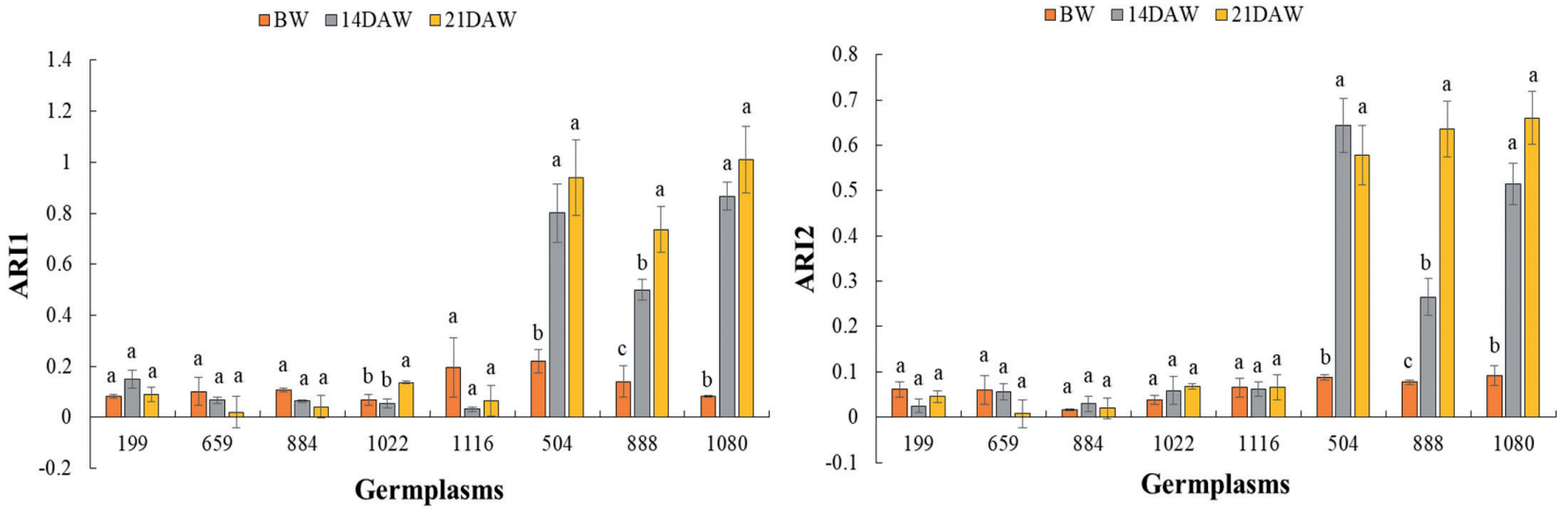

Fig. 4. Changed in the vegetation indices of the selected contrasting wild soybean accessions under waterlogging conditions. In the figure, different letters in error bars indicate significant different by Duncan's multiple range test $(P<0.05)$.
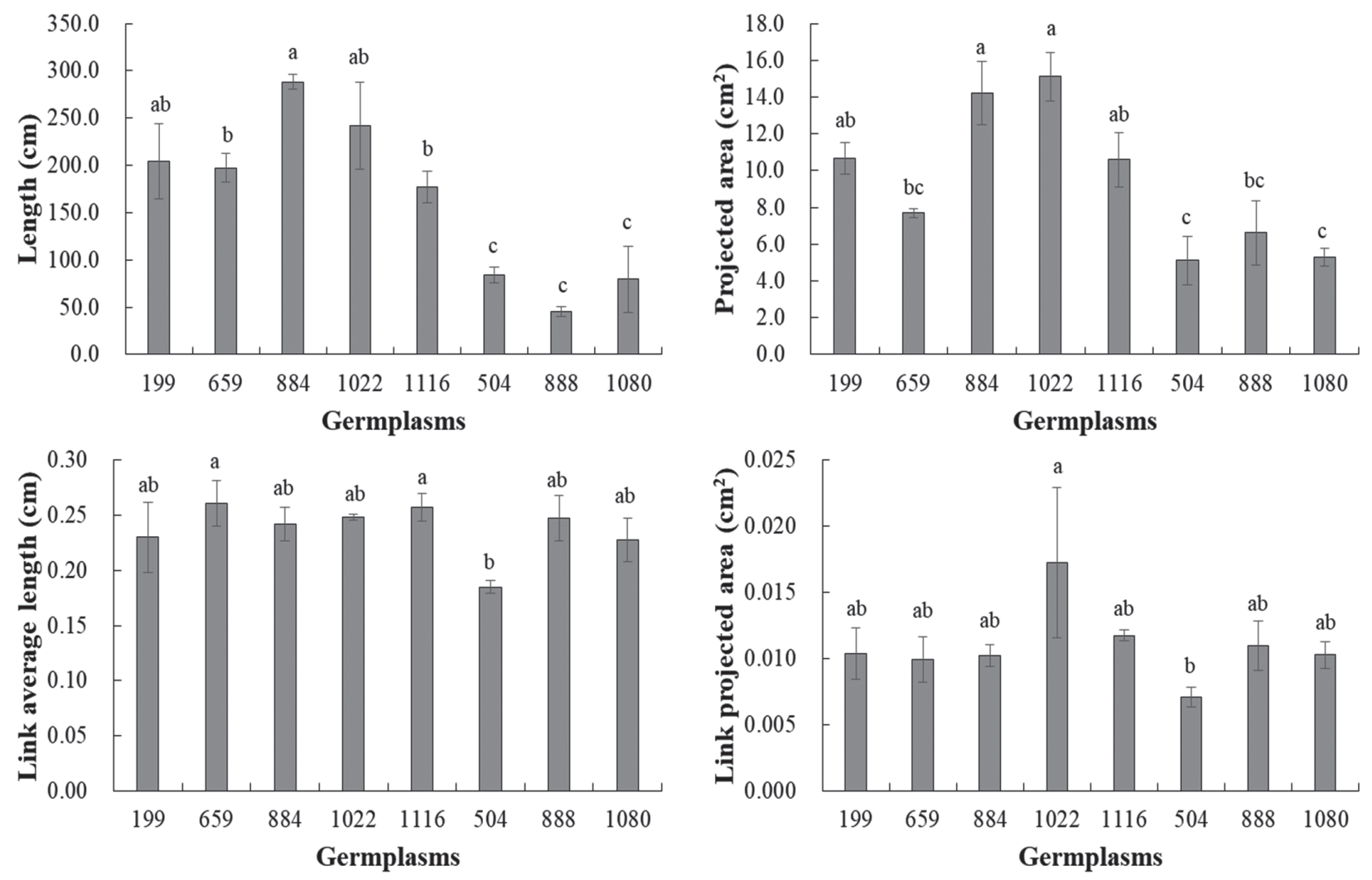

Fig. 5. Influence of root morphological traits in the selection of contrasting wild soybean accessions under waterlogging conditions. In the figure, different letters in the error bars indicate significant differences by the Duncan's multiple range test $(P<0.05)$. 
The link projected area was the highest in accession 1,022 and lowest in accession 504 (Fig. 5). Other accessions did not show a statistical difference for this trait (Fig. 5). The link projected area of accession 1,022 was $0.017 \mathrm{~cm}^{2}$ and that of accession 504 was $0.007 \mathrm{~cm}^{2}$; therefore, tolerant accession 1,022 was 58.8\% higher than susceptible accession 504 (Fig. 5).

\section{Discussion}

Soybean is an economically important crop as it is a source of food, feed, and biofuel [19]. However, unexpected weather events, such as excess water levels in the field, negatively affect the soybean yield [4]. Therefore, the development of new soybean accessions is required for enhancing the productivity of soybean in various field conditions. To develop new varieties, finding variations in accessions is very important. Glycine max showed narrower genetic variations than Glycine soja due to genetic bottlenecks and manual selection $[19,20]$. Therefore, it is essential to find out the novel variations found in wild soybean accessions $[20,21]$. Both cultivated and wild soybeans belong to the genus Glycine, and wild soybeans are considered the ancestors of cultivated soybean; therefore, wild soybeans can be used for their genetic materials to improve various characteristics in cultivated soybean $[19,21,22]$. Despite of the importance of wild soybean for its genetic resources, the morphological traits of the shoot and root under waterlogging stress has not been characterized to date. Therefore, we used 164 wild soybean accessions and tested them to evaluate their stress responses for selecting contrasting wild soybean accessions. All potted plants were transferred to a pool of water to ensure a stress condition when overall wild soybean plants reached the V1 growth stage. For 2 weeks, a water level of 4-6 cm from the surface was maintained and then visual rating was performed on a 1-5 visual scoring scale at 14 and 21 DAW because visual rating is the most important method for selecting or evaluating stress resistance in certain conditions, such as drought stress [23], flooding stress [24], cyst nematode infestation [25] and two-spotted spider mite invasion [26].

In an experiment that was previously conducted, the waterlogging condition was for cultivated soybeans was maintained for 14 days and visual rating was performed on a 1-5 scale throughout the period [20]. In a similar experiment, waterlogging condition was maintained for 8-11 days and foliar damage or senescence was measured on a 1-9 visual scoring scale [27]. For waterlogging, the stress exposure period is an important factor because some genotypes may show similar responses when they are exposed to such stresses for too long or too short a period. In this experiment, the waterlogging condition was maintained for 14 days because the duration was relevant to the purpose of this experiment.
Various research groups have attempted to evaluate waterlogging tolerance and susceptibility in cultivated soybean since then; however, similar researches in wild soybeans are lacking [20, 27]. In another experiment, waterlogging tolerance and susceptibility was evaluated using 722 cultivated soybeans (maturity groups 4 and 5) for 5 years and reported that 52 soybeans showed tolerance and 57 soybeans demonstrated high sensitivity to waterlogging [27]. This shows that almost an equal number of cultivars were tolerant and sensitive to waterlogging. However, in this experiment, a greater number of wild soybean cultivars were waterloggingtolerant (Fig. 3). Perhaps, these results are induced by the genetic diversity of wild soybean accessions. Studies have reported that wild soybeans have high adaptation to unfavorable environmental conditions [28, 29]. Therefore, only a small number of wild soybean accessions have been identified as waterloggingsusceptible.

The wilting status of plants was used for standard stress tolerance and susceptibility evaluation. Therefore, the wilting score has been used for selecting resistant genotypes in soybean [7, 20]. For this evaluation, breeders' experience is of utmost importance for accurate evaluation because plants can wilt even when exposed to various stress conditions. Furthermore, the range of the wilting score is not highly varying; therefore, breeders face this difficulty when the plants show moderate resistance. Subsequently, changes in leaf color, such as chlorophyll content and SPAD measurement, provide an alternative index for evaluating stress resistance [30, 31]. Recently, vegetation indices have been broadly used for predicting plant growth conditions [32]. The measurement of vegetation indices is highly preferred for high-throughput phenotyping due to its ease in obtaining data using a spectral camera and its large-scale coverage in the field [32]. In this experiment, chlorophyll content did not show any correlation with visual rating; however, several other vegetation indices showed high correlation with visual score (Table 4). Although there was a statistical correlation between visual scores and vegetation indices, the range of correlation value was low. The reason for this could be the similarity in visual scores for roughly $90 \%$ of the wild soybean accessions. Another reason could be the difference in the values of the visual scores and vegetation indices. As a result, correlation analysis was re-performed by selecting contrasting accessions. Therefore, only four vegetation indices with high correlation were confirmed, namely SPRI, ARI1, ARI2, and PRI. In particular, ARI1, ARI2, and PRI showed high correlational values for both measurements. ARI1 and ARI2 predict anthocyanin content via a nondestructive method and have been developed by the Gitelson [33]. Anthocyanins are known as water-soluble pigments derived from the flavonoids of higher plants and are responsible for the red coloration in plants [33]. Anthocyanins are accumulated in stress conditions, such as strong light, drought, fungal infection, nitrogen 
deficiency, and waterlogging [33-35]. In the present experiment, susceptible wild soybeans rapidly increased the development of red coloration in their leaves (Fig. 2). This led to a high correlation between visual scores and ARI1 and ARI2. PRI is based on the xanthophyll cycle pigment. Therefore, it reflects leaf fluorescence and photosynthesis [34]. For this reason, PRI has been used to detect water stress in crops [36, 37].

Root morphological traits are very important for water and nutrient uptake in plants and are widely studied for enhancing crop productivity [38]. Furthermore, various root morphological traits respond to osmotic stress conditions, such as drought and waterlogging [4, 38, 39]. Therefore, the root morphological traits between waterlogging-tolerant and waterlogging-susceptible accessions were analyzed and compared. The results indicated that waterloggingtolerant accessions commonly show higher root length and root projected area than susceptible accessions. It has been reported that exogenously applied ethylene improves waterlogging resistance in Glycine max due to increased root surface area [4].

\section{Conclusions}

The waterlogging tolerance and susceptibility of 164 wild soybean genotypes were tested in three replicates. Our experiments confirmed that several wild soybean accessions are waterlogging-resistant. Furthermore, vegetation indices were observed to show a high correlation with visual score; therefore, they could be used as predictors of waterlogging resistance and susceptibility. In particular, ARI and PRI could be appropriate for precise accession screening. Therefore, those selected wild soybean accessions can be used for relevant researches.

\section{Acknowledgements}

This work was conducted with the support of the "Cooperative ResearchProgram for Agriculture Science \& Technology Development (Project No. PJ01416803)" Rural Development Administration, Republic of Korea.

\section{Conflict of Interest}

The authors declare no conflict of interest.

\section{References}

1. ZHANG Y., KONG X., DAI J., LUO Z., LI Z., LU H., XU S., TANG W., ZHANG D., LI W., XIN C., DONG H. Global gene expression in cotton (Gossypium hirsutum L.) leaves to waterlogging stress. PLoS One, 12 (9), e0185075, 2017.
2. REHMAN A., JINGDONG L., DU Y., KHATOON R., WAGAN S.A., NISAR S.K. Flood disaster in Pakistan and its impact on agriculture growth (a review). Environ. Dev. Econ. 6 (23), 39, 2015.

3. ARDUINI I., BALDANZI M., PAMPANA S. Reduced growth and nitrogen uptake during waterlogging at tillering permanently affect yield components in late sown oats Front. Plant Sci. 10, 1087, doi: 10.3389/fpls.2019.01087, 2019.

4. KIM Y., SEO C.W., KHAN A.L., MUN B.G., SHAHZAD R., KO J.W., YUN B.W., PARK S.K., LEE I.J. Exoethylene application mitigates waterlogging stress in soybean (Glycine max L.). BMC Plant Biol. 18, 254, 2018.

5. FUKAO T., BARRERA-FIGUEROA B.E., JUNTAWONG P., PEÑA-CASTRO J.M. Submergence and Waterlogging Stress in Plants: A Review Highlighting Research Opportunities and Understudied Aspects. Front. Plant Sci. 10, 340, 2019.

6. VALLIYODAN B., YE H., SONG L., MURPHY M., SHANNON J.G., NGUYEN H.T. Genetic diversity and genomic strategies for improving drought and waterlogging tolerance in soybeans. J .Exp. Bot. 68 (8), 1835., 2017.

7. NGUYEN V., VUONG T., VANTOAI T., LEE J., WU X., MIAN M., DORRANCE A., SHANNON J., NGUYEN H. Mapping of quantitative trait loci associated with resistance to Phytophthora sojae and flooding tolerance in soybean. Crop Sci. 52, 2481, 2012.

8. WANG X., HUANG M., ZHOU Q., CAI J., DAI T., CAO W., JIANG D. Physiological and proteomic mechanisms of waterlogging priming improves tolerance to waterlogging stress in wheat (Triticum aestivum L.). Environ. Exp. Bot. 132, 175, 2016.

9. REN C., KONG C., YAN K. ZHANG H., LUO YM., XIE Z.H. Elucidation of the molecular responses to waterlogging in Sesbania cannabina roots by transcriptome profiling. Sci. Rep. 7, 92562017.

10. MILLAR A.H., WHELAN J., SOOLE K.L., DAY D.A. Organization and regulation of mitochondrial respiration in plants. Annu. Rev. Plant Biol. 62, 79, 2011.

11. KIM Y.H., HWANG S.J., WAQAS M., KHAN A.L., LEE J.H., LEE J.D., NGUYEN H.T., LEE I.J. Comparative analysis of endogenous hormones level in two soybean (Glycine $\max \mathrm{L}$.) lines differing in waterlogging tolerance. Front. Plant Sci. 6, 714, 2015.

12. MOHAMMED U., CAINE R.S., ATKINSON J.A. HARRISON E.L., WELLS D., CHATER C.C., GRAY J.E., SWARUP R., MURCHIE E.H., Rice plants overexpressing OSEPF1 show reduced stomatal density and increased root cortical aerenchyma formation. Sci. Rep. 9, 5584, 2019.

13. VANTOAI T.T., ST MARTIN S.K., CHASE K., BORU G., SCHNIPKE V., SCHMITTHENNER A.F., LARK K.G. Identification of a QTL associated with tolerance of soybean to soil waterlogging. Crop Sci. 41, 1247, 2001.

14. CORNELIOUS B., CHEN P., HOU A., SHI A., SHANNON J. Yield potential and waterlogging tolerance of selected near-isogenic lines and recombinant inbred lines from two southern soybean populations. J. Crop Improv. 16, 97, 2006.

15. YE H., SONG L., CHEN H., VALLIYODAN B., CHENG P., ALI L., VUONG T., WU C., ORLOWSKI J., BUCKLEY B. A major natural genetic variation associated with root system architecture and plasticity improves waterlogging tolerance and yield in soybean. Plant Cell Environ. 41, 2169, 2018.

16. MICKELBART M.V., HASEGAWA P.M., BAILEYSERRES J. Genetic mechanisms of abiotic stress tolerance 
that translate to crop yield stability. Nat. Rev. Genet. 16, 237, 2015.

17. ZHANG H., MITTAL N., LEAMY L.J., BARAZANI O., SONG B.H. Back into the wild-apply untapped genetic diversity of wild relatives for crop improvement. Evol. Appl. 10, 5, 2017.

18. MAMMADOV J., BUYYARAPU R., GUTTIKONDA S.K., PARLIAMENT K., ABDURAKHMONOV I.Y., KUMPATLA S.P. Wild relatives of maize, rice, cotton, and soybean: treasure troves for tolerance to biotic and abiotic stresses. Front. Plant Sci. 9, 886, 2018.

19. NAWAZ M.A., LIN X., CHAN T.F., HAM J., SHIN T.S., ERCISLI S., GOLOKHVAST K.S., LAM H.M., CHUNG G. Korean wild soybeans (Glycine soja Sieb \& Zucc.): geographic distribution and germplasm conservation. Agronomy. 10, 214, 2020.

20. HYTEN D.L., SONG Q., ZHU Y., CHOI I.Y., NELSON R.L., COSTA J.M., SPECHT J.E., SHOEMAKER R.C., CREGAN P.B. Impacts of genetic bottlenecks on soybean genome diversity. Proc. Natl. Acad. Sci. 103, 16666, 2006.

21. COWLING W., LI L., SIDDIQUE K.H., HENRYON M., BERG P., BANKS R., KINGHORN B. Evolving gene banks: improving diverse populations of crop and exotic germplasm with optimal contribution selection. J. Exp. Bot. 68, 1927, 2017.

22. MUÑOZ N., LIU A., KAN L., LI M.W., LAM H.M. Potential uses of wild germplasms of grain legumes for crop improvement. Int. J. Mol. 18, 328, 2017.

23. NAWAZ MA, GOLOKHVAST KS, REHMAN HM, TSUKAMOTO C, KIM H.S., YANG SH., CHUNG G. Soyisoflavone diversity in wild soybeans (Glycine soja Sieb. \& Zucc.) from the main centres of diversity. Biochem. Syst. Ecol. 77, 16, 2018.

24. RHINE M.D., STEVENS G., SHANNON G., WRATHER A., SLEPER D. Yield and nutritional responses to waterlogging of soybean cultivars. Irrig. Sci. 28, 135, 2010.

25. BAJWA S.G., RUPE J.C., MASON, J. Soybean disease monitoring with leaf reflectance. Remote Sens. 9 (2), 127. 2017.

26. HUANG H., DENG J., LAN Y., YANG A., DENG X., ZHANG L., WEN S., JIANG Y., SUO G., CHEN P. A two-stage classification approach for the detection of spider mite-infested cotton using UAV multispectral imagery. Remote Sens. Lett. 9 (10), 933, 2018.

27. WU C., ZENG A., CHEN P., HUMMER W., MOKUA J., SHANNON J.G., NGUYEN H.T. Evaluation and development of flood-tolerant soybean cultivars. Plant Breed. 136, 913, 2017.
28. ANDERSON J.E., KONO T.J., STUPAR R.M., KANTAR M.B., MORRELL P.L. Environmental association analyses identify candidates for abiotic stress tolerance in Glycine soja, the wild progenitor of cultivated soybeans. G3: Genes, Genomes, Genetics, 6 (4), 835, 2016.

29. SHARMIN R.A., BHUIYAN M.R., LV W., YU Z., CHANG F., KONG J., BHAT J.A., ZHAO T. RNA-Seq based transcriptomic analysis revealed genes associated with seed-flooding tolerance in wild soybean (Glycine soja Sieb. \& Zucc.). Environ. Exp. Bot. 171, 103906, 2020.

30. HAMAYUN M., KHAN S.A., IQBAL A., HUSSAIN A., LEE IJ. Cheap and rigorous method of screening soybean cultivars for drought tolerance. Fresenius Environ. Bull. 28, 8568, 2019.

31. HAMAYUN M., KHAN S.A., IQBAL A., HUSSAIN A., LEE IJ. Screening of soybean cultivars for salinity tolerance under hydroponics, Fresenius Environ. Bull. 28, 7955, 2019.

32. XUE J., SU B. Significant remote sensing vegetation indices: A review of developments and applications. J. Sens. 2017, Article ID 1353691, 2017.

33. GITELSON A.A., MERZLYAK M.N., CHIVKUNOVA O.B. Optical properties and nondestructive estimation of anthocyanin content in plant leaves. Photochem. Photobiol. 74, 38, 2001.

34. KIM J., LEE W.J., VU T.T., JEONG C.Y., HONG S.W., LEE $H$. High accumulation of anthocyanins via the ectopic expression of AtDFR confers significant salt stress tolerance in Brassica napus L. Plant Cell Rep. 36 (8), 1215, 2017.

35. CLOSE D., DAVIDSON N. Long-term waterlogging: nutrient, gas exchange, photochemical and pigment characteristics of Eucalyptus nitens saplings. Russ. J. Plant Physl. 50, 843, 2003.

36. LI M., CHU R., YU Q., ISLAM A.R.M., CHOU S., SHEN S. Evaluating structural, chlorophyll-based and photochemical indices to detect summer maize responses to continuous water stress. Water. 10, 500, 2018.

37. DOTZLER S., HILL J., BUDDENBAUM H., STOFFELS J. The potential of EnMAP and Sentinel-2 data for detecting drought stress phenomena in deciduous forest communities. Remote Sens. 7, 14227, 2015.

38. PAEZ-GARCIA A., MOTES C.M., SCHEIBLE W.R., CHEN R., BLANCAFLOR E.B., MONTEROS M.J. Root traits and phenotyping strategies for plant improvement. Plants. 4, 334, 2015.

39. KUNERT K.J., VORSTER B.J., FENTA B.A., KIBIDO T., DIONISIO G., FOYER C.H. Drought stress responses in soybean roots and nodules. Front. Plant Sci. 7, 1, 2016. 


\section{Supplementary Material}

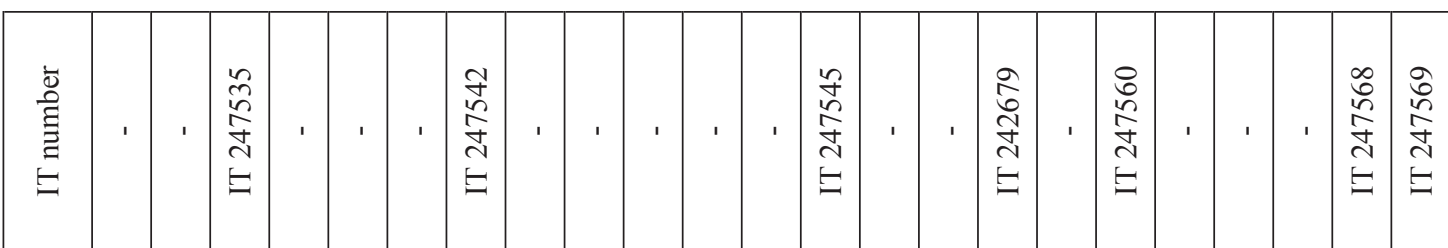

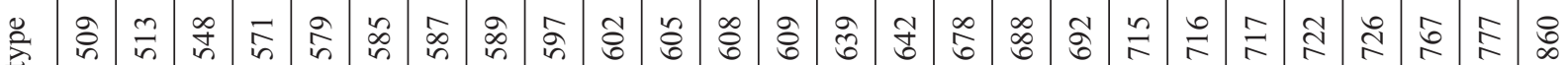

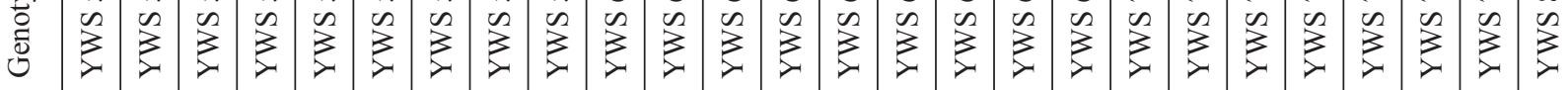

畫总

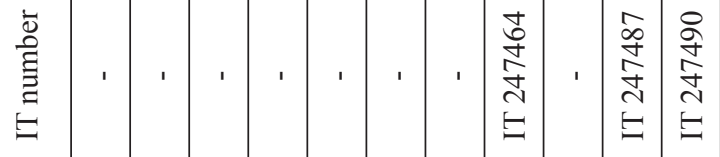

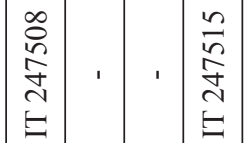

$\frac{2}{\frac{n}{r}}$

$\Xi$

$\stackrel{E}{\sqrt{2}}$

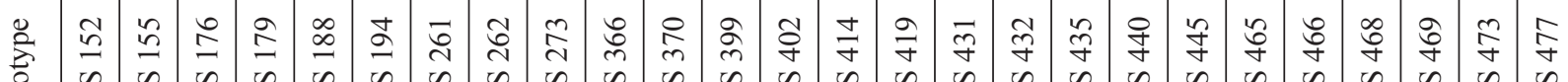

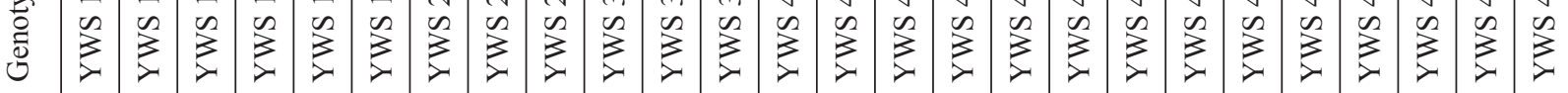

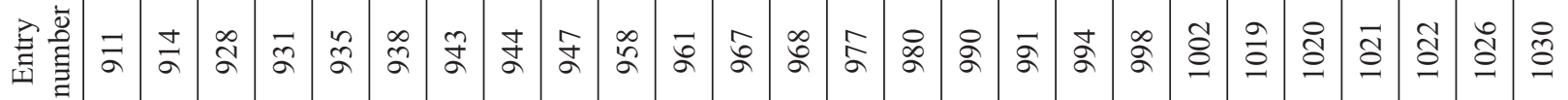

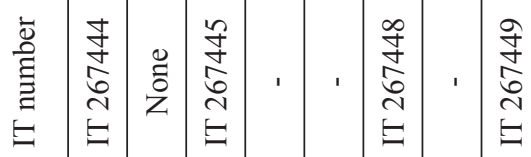

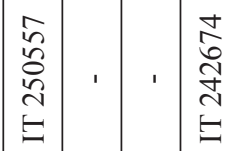

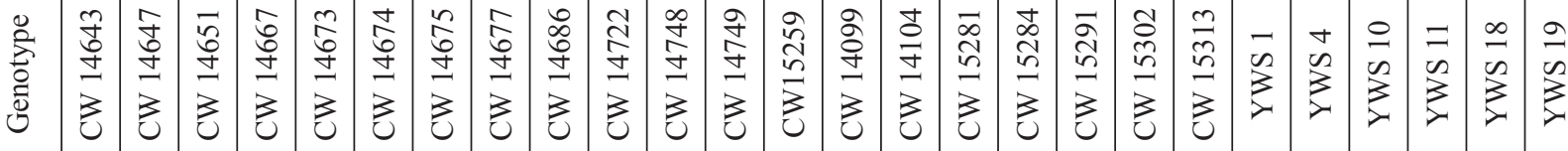

在离苛

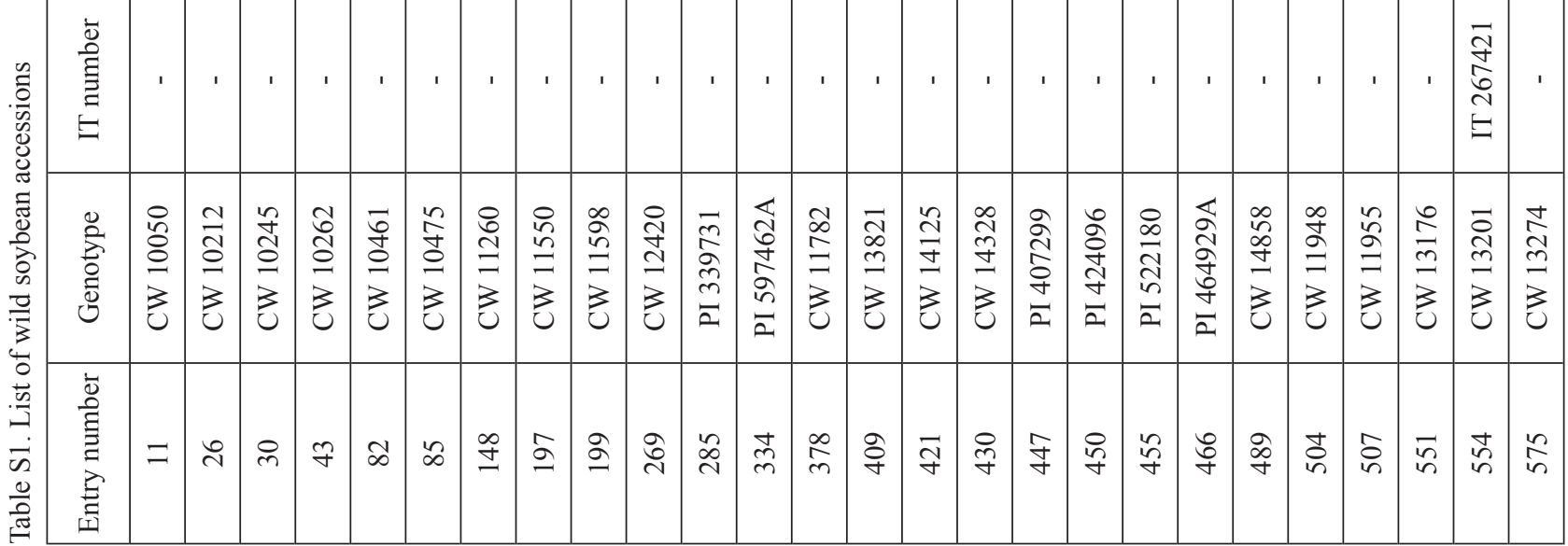




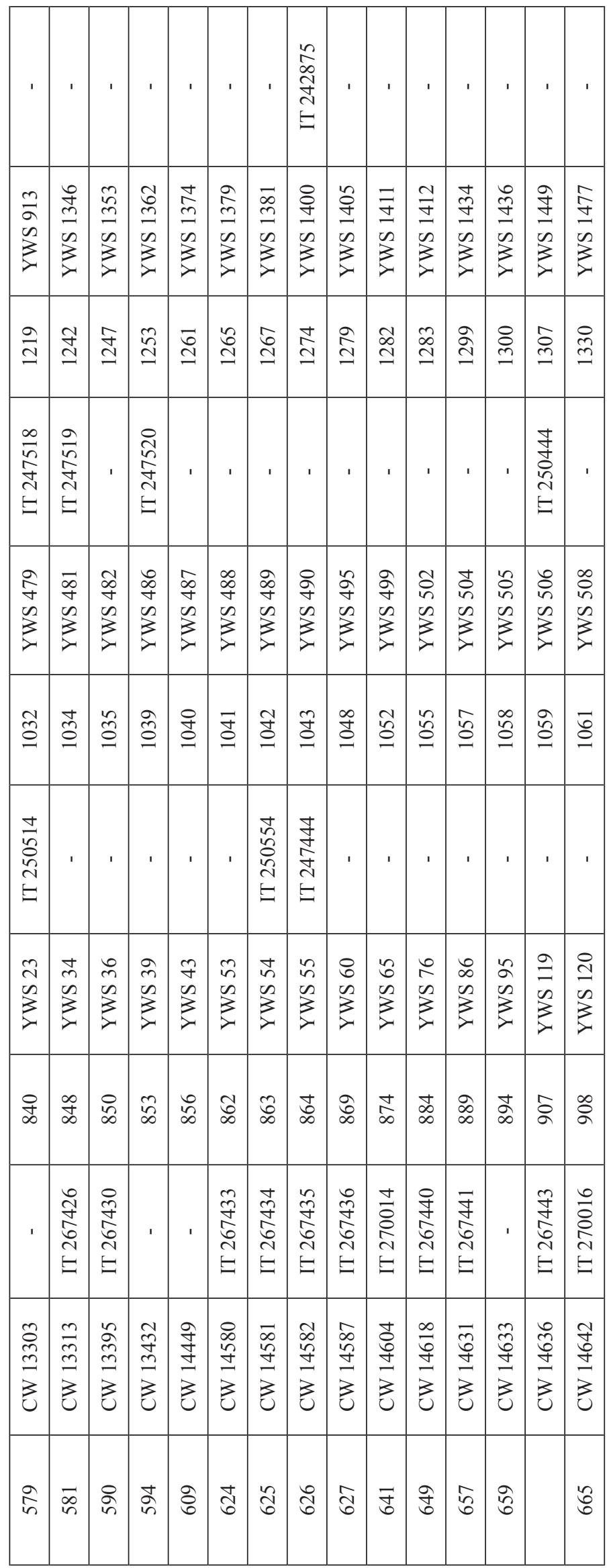


Table S2. Equations of the vegetation indices.

\begin{tabular}{|c|c|}
\hline Index & Formula \\
\hline $\begin{array}{l}\text { Normalized Difference Vegetation Index } \\
\text { (NDVI) }\end{array}$ & $\mathrm{NDVI}=\frac{R_{N I R}-R_{R E D}}{R_{N I R}+R_{R E D}}$ \\
\hline Simple Ratio Index (SR) & $\mathrm{SR}=\frac{R_{N I R}}{R_{R E D}}$ \\
\hline $\begin{array}{l}\text { Modified Chlorophyll Absorption in Reflectance Index } \\
\text { (MCARI1) }\end{array}$ & MCARI $1=1.2 \times\left[2.5 \times\left(R_{790}-R_{670}\right)-1.3 \times\left(R_{790}-R_{550}\right)\right]$ \\
\hline Optimized Soil-Adjusted in Reflectance Index (OSAVI) & OSAV $\mathrm{I}=(1+0.16) \times \frac{\left(R_{790}-R_{670}\right)}{\left(R_{790}+R_{670}+0.16\right)}$ \\
\hline Greenness Index $(\mathrm{G})$ & $\mathrm{G}=\frac{R_{554}}{R_{667}}$ \\
\hline $\begin{array}{l}\text { Modified Chlorophyll Absorption in Reflectance Index } \\
\text { (MCARI) }\end{array}$ & $\operatorname{MCARI}=\left[\left(R_{700}-R_{670}\right)-0.2 \times\left(R_{700}-R_{550}\right)\right] \times\left(\frac{R_{700}}{R_{670}}\right)$ \\
\hline Transformed CAR Index (TCARI) & $\mathrm{TCARI}=3 \times\left[\left(R_{700}-R_{670}\right)-0.2 \times\left(R_{700}-R_{550}\right)\right] \times\left(\frac{R_{700}}{R_{670}}\right)$ \\
\hline Traiangular Vegetation Index (TVI) & $\mathrm{TVI}=0.5 \times\left[120 \times\left(R_{750}-R_{550}\right)-200 \times\left(R_{670}-R_{550}\right)\right]$ \\
\hline Zarco-Tejada \& Miller (ZMI) & $\mathrm{ZMI}=\frac{R_{750}}{R_{710}}$ \\
\hline Simple Ratio Pigment Index (SRPI) & $\mathrm{SRPI}=\frac{R_{430}}{R_{680}}$ \\
\hline Normalized Phaeophytinization Index (NPQI) & $\mathrm{NPQI}=\frac{R_{415}-R_{435}}{R_{415}+R_{435}}$ \\
\hline Photochemical Reflectance Index (PRI) & $\mathrm{PRI}=\frac{R_{531}-R_{570}}{R_{531}+R_{570}}$ \\
\hline Normalized Pigment Chlorophyll Index (NPCI) & $\mathrm{NPCI}=\frac{R_{680}-R_{430}}{R_{680}+R_{430}}$ \\
\hline Carter Stress Index (Ctr1) & $\operatorname{Ctr} 1=\frac{R_{695}}{R_{420}}$ \\
\hline Carter Stress Index (Ctr2) & $\mathrm{Ctr} 2=\frac{R_{695}}{R_{760}}$ \\
\hline Lichtenthaler Index (Lic1) & Lic1 $=\frac{R_{790}-R_{680}}{R_{790}+R_{680}}$ \\
\hline Lichtenthaler Index (Lic2) & $\operatorname{Lic} 2=\frac{R_{440}}{R_{690}}$ \\
\hline Structure insensitive pigment index (SIPI) & $\mathrm{SIPI}=\frac{R_{790}-R_{450}}{R_{790}-R_{650}}$ \\
\hline Gitelson \& Merzlyak Index (GM1) & $\mathrm{GM} 1=\frac{R_{750}}{R_{550}}$ \\
\hline Gitelson \& Merzlyak Index (GM2) & $\mathrm{GM} 2=\frac{R_{750}}{R_{700}}$ \\
\hline Anthocyanin Reflectance Index (ARI1) & $\mathrm{ARI} 1=\frac{1}{R_{550}}-\frac{1}{R_{700}}$ \\
\hline Anthocyanin Reflectance Index (ARI2) & $\mathrm{ARI} 2=R_{800} \times\left(\frac{1}{R_{550}}-\frac{1}{R_{700}}\right)$ \\
\hline Carotenoid Reflectance Index 1 (CRI1) & $\mathrm{CRI} 1=\frac{1}{R_{510}}-\frac{1}{R_{550}}$ \\
\hline Carotenoid Reflectance Index 1 (CRI2) & $\mathrm{CRI} 2=\frac{1}{R_{510}}-\frac{1}{R_{700}}$ \\
\hline Renormalized Difference Vegetation Index (RDVI) & $\mathrm{RDVI}=\frac{R_{N I R}-R_{R E D}}{\sqrt{R_{N I R}+R_{R E D}}}$ \\
\hline
\end{tabular}

